\title{
К ВОПРОСУ ОЦЕНКИ ЭФФЕКТИВНОСТИ ФИНАНСИРОВАНИЯ ВЫСШИХ УЧЕБНЫХ ЗАВЕДЕНИЙ НА ОСНОВЕ АНАЛИЗА РЕЙТИНГА ПРОФЕССОРСКО- ПРЕПОДАВАТЕЛЬСКОГО СОСТАВА
}

\author{
(c) 2019 Николаева Елена Анатольевна \\ кандидат социологических наук, доцент, кафедра иностранных языков № 3 \\ Российский экономический университет им. Г.В. Плеханова, Россия, Москва \\ E-mail: yoltash82@mail.ru \\ (c) 2019 Казимирова Ирина Сергеевна \\ кандидат филологических наук, доцент, кафедра иностранных языков № 3 \\ Российский экономический университет им. Г.В. Плеханова, Россия, Москва \\ E-mail: irinacasimirova@yandex.ru \\ (c) 2019 Панченко Екатерина Юрьевна \\ старший преподаватель, кафедра иностранных языков № 3 \\ Российский экономический университет им. Г.В. Плеханова, Россия, Москва \\ E-mail:katya368@yandex.ru \\ (C) 2019 Родникова Оксана Юрьевна \\ старший преподаватель, кафедра иностранных языков № 3 \\ Российский экономический университет им. Г.В. Плеханова, Россия, Москва \\ E-mail: orodnikova@yahoo.es
}

В статье авторов рассмотрен вопрос оценки эффективности финансирования высших учебных заведений на основе анализа рейтинга профессорско-преподавательского состава. Объектом исследования выступили высшие учебные заведения Российской Федерации, а предметом - эффективность их финансирования в аспекте анализа рейтинга профессорско-преподавательского состава. Теоретическое и методологическое значения исследования заключены в развитии теории оптимального финансирования экономических субъектов. Практическое значение исследования определяется возможностью принятия сбалансированных решений в управлении высшим ученым заведением во взаимосвязи с анализом рейтинга профессорско-преподавательского состава.

Ключевые слова: Высшее учебное заведение, финансирование, оценка эффективности, анализ, рейтинг, профессорско-преподавательский состав.

В условиях комплексной оптимизации расходов федерального бюджета Российской Федерации значительную актуальность приобретают вопросы финансирования бюджетных учреждений [6, с. 468].

По мнению аналитиков рейтингового агентства «Эксперт РА» наиболее значимые изменения в подходах к финансированию субъектов Российской Федерации из бюджета в 2020-2023 годах с вероятностью порядка 93,79\% произойдут в сферах образования (в первую очередь, высшего профессионального образования), здравоохранения и социального обеспечения населения страны [10]. Порядок значимости в обозначенных сферах на трехлетний период оценен в $35,25 \%, 28,39$ и 21,57\% соответственно для каждой из обозначенных сфер в Российской
Федерации [10].

Исходя из того, что наиболее значимые изменения в Российской Федерации могут иметь место в сфере финансирования высшего профессионального образования [2, с. 87], рассмотрим обозначенный вопрос в данной проекции более подробно.

Для комплексного понимания состояния вопроса финансирования высших учебных заведений [3, с. 37] в Российской Федерации была изучена его эффективность в динамическом аспекте за последние пять лет и составлено специализированное поле, усредненные показатели которого приведены на рисунке 1 . Из рисунка можно увидеть, что за обозначенный период времени значения анализируемого показателя, в целом (за исключением 2017 года - значение показа- 


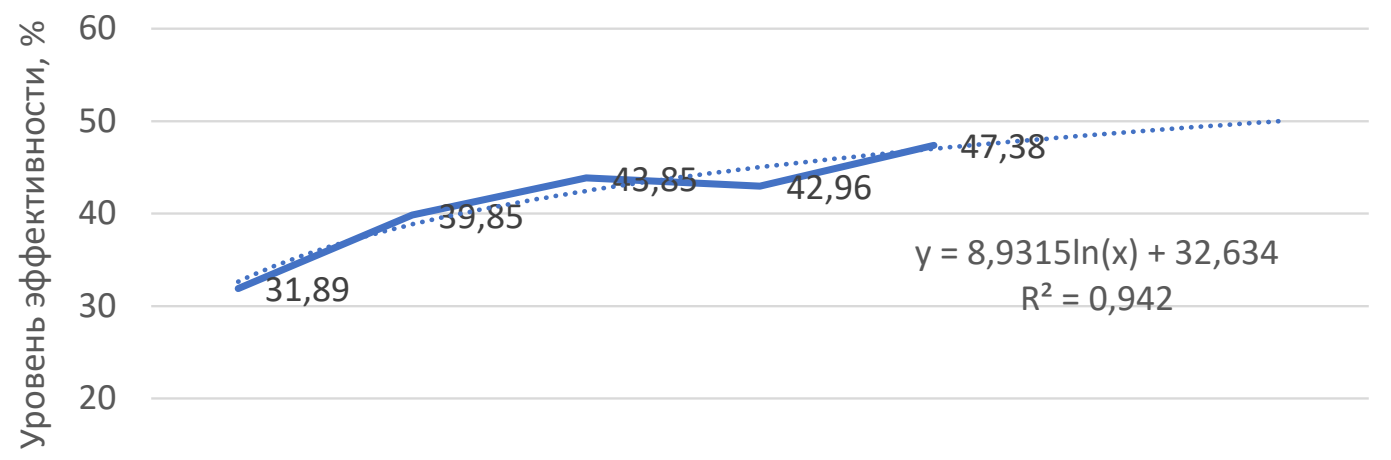

10

0

$2014 \quad 2015 \quad 2016 \quad 2017 \quad 2018$

Годы

Puc. 1. Усредненные показатели поля эффективности финансирования высших учебных заведений в Российской Федерации за 2014-2018 годы [9]

теля здесь снизилось до 42,96\%), изменялись в положительном направлении и к 2018 году достигли 47,38\% из 100 возможных. При этом с вероятностью 94,2\% (данные на основе смоделированной логарифмической кривой) к 2020 году показатель эффективности финансирования может достичь комфортного для Российской Федерации значения в 50\%.

Несмотря на достаточно высокие усредненные значения анализируемого показателя, относительно мировой статистики (например, средний уровень эффективности финансирования высших учебных заведений в США [7, 8] из бюджета в 2018 году составил более 83,85\%, а с высших учебных заведениях Англии - порядка 91\%) [4, 5, 9], уровень эффективности финансирования высших учебных заведений в Российской Федерации имеет существенный задел по их оптимизации.

Основными моментами, по мнению авторов, препятствующими в настоящее время высшим учебным заведениям Российской Федерации [1, с. 64] достичь более оптимальных значений эффективности в аспекте финансирования их деятельности являются:

- несбалансированность процесса оценки эффективности финансирования высших учебных заведений (в настоящее время комплексная методика в данном аспекте, по мнению многих исследователей, не является оптимальной. Более того, отдельные ее элементы, связанные, например, с научной исследовательской работой, явно выделяются, как противоречивые и вызывают значительный объем критики);

- высокий уровень субъективности в распределении полученных средств между подразделениями высших учебных заведений (зачастую, в высших учебных заведениях Российской Федерации доступ к финансированию проектов в полном объеме получают лишь профильные подразделения, что приводит к недостатку средств для прочих, но не менее перспективных в плане эффективности использования денежных средств подразделений);

- значительная универсальность формирования рейтинга профессорско-преподавательского состава, препятствующая персонализации поддержки наиболее эффективных кадровых единиц в составе высшего учебного заведения в Российской Федерации (в настоящее время, к сожалению, многие таланливые и перспективные кадровые единицы не получают должной финансовой поддержки, ввиду незначительности опыта их работы в высшем учебном заведении и низкого значения индексируемых показателей, принятых к интегральному анализу научных сотрудников в Российской Федерации - индекс цитирования, h-индекс и прочие).

Распределение значимости обозначенных моментов, в аспекте влияния на оптимизацию уровня эффективности финансирования высших учебных заведений в Российской Федерации на 2020-2021 годы приведено на рисунке 2.

Как можно увидеть из рисунка - в наиболь- 


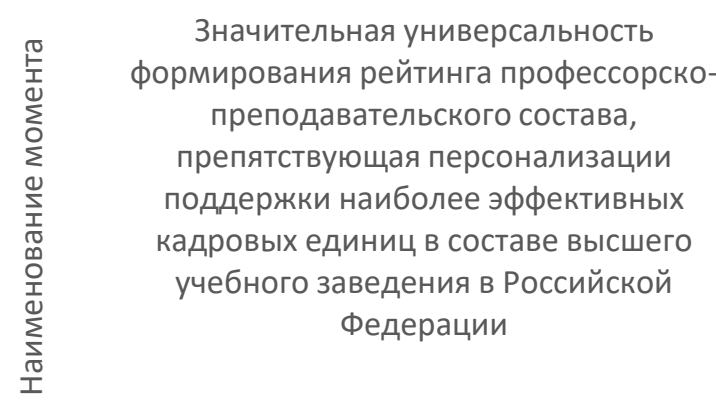

Высокий уровень субъективности в распределении полученных средств между подразделениями высших учебных заведений

Несбалансированность процесса оценки эффективности финансирования высших учебных заведений



Puc. 2. Распределение значимости обозначенных моментов, в аспекте влияния на оптимизацию уровня эффективности финансирования высших учебных заведений в Российской Федерации на 2020-2021 годы

шей степени на оптимизацию уровня эффективности финансирования высших учебных заведений в Российской Федерации влияют:

- значительная универсальность формирования рейтинга профессорско-преподавательского состава (уровень значимости данного момента обозначен комиссией экспертов в 5 единиц из 10 возможных);

- далее следует момент, связанный с несбалансированностью процесса оценки эффективности финансирования высших учебных заведений (уровень значимости обозначенного момента определен комиссией экспертов в 3 единицы из 10 возможных);

- в завершении перечня идет момент, содержащий высокий уровень субъективности в распределении полученных средств между подразделениями высших учебных заведений (уровень значимости указанного момента определен комиссией экспертов в 2 единицы из 10 возможных).
В целях изменения состава, указанных выше моментов и повышения эффективности финансирования высших учебных заведений в Российской Федерации в будущем, целесообразно, на наш взгляд, провести следующие инициативы:

- модернизировать процесс оценки эффективности финансирования высших учебных заведений (основываясь на международном опыте $[5,7,9]$ решения аналогичных вопросов здесь, на наш взгляд, целесообразно применить методику «Пирамиды достижений"» и комплексно изменить сам поход к оценке, принимая во внимание не только параметры объектов анализа, но и параметры взаимосвязей между ними, используя при этом проекции как внутренней, так и внешней для высшего учебного заведения эффективности);

- разработать и внедрить на федеральном уровне механизм распределения полученных высшими учебными заведениями денежных средств по их подразделениям (здесь наиболее

"В классическом англоязычном представлении - Performance Pyramid. 
оптимальным решением может служить создание в высших учебных заведениях «Интегральных объектов» или «Кластеров», объединяющих усилия разноплановых подразделений по финансовым, информационным и методическим проекциям. При этом процесс объединения будет носить лишь виртуальный характер и не затрагивать самостоятельность конкретных подразделений высшего учебного заведения как такового);

- специализировать процесс формирования рейтинга профессорско-преподавательского состава для устранения препятствий персонализации поддержки наиболее эффективных кадровых единиц, работающих в высших учебных заведениях (при разрешении данного момента необходимо, на наш взгляд, сделать акцент на внедрении в систему формирования рейтинга профессорско-преподавательского состава высшего учебного заведения определенных корректировок (поправок) для кадровых единиц, ввиду объективных причин, в полной мере не адаптированных к трудовому процессу в существующем объекте анализа. На наш взгляд, в первую очередь, данные поправки должны отразиться на вновь принятых, ротированных и переквалифицированных единицах персонал высших учебных заведений Российской Федерации).

Указанные выше инициативы целесообразно, на наш взгляд, целесообразно провести в рамках следующих этапов:

- модернизация нормативно-правовой базы на федеральном уровне (общая и специальная часть);

- модернизация организационных регламентов функционирования высших учебных заведений;

- модернизация методической базы функционирования высших учебных заведений;
- модернизация информационной базы функционирования высших учебных заведений;

- формирование регламентов проверки выполнения высшими учебных заведений обозначенных мероприятий;

- проведение на систематической основе комплекса контрольно-ревизионных мероприятий в выборочным высших учебных заведения в Российской Федерации;

- проведение корректировок рассмотренных выше инициатив по результатам проведенных проверок высших учебных заведений Российской Федерации.

Таким образом, можно сделать вывод, что процесс оценки эффективности финансирования высших учебных заведений на основе анализа рейтинга профессорско-преподавательского состава в Российской Федерации сопряжен в настоящее время с целям рядом проблемных моментов, связанных с: несбалансированностью процесса оценки эффективности высших учебных заведений; высоким уровнем субъективности в распределении полученных средств между подразделениями высших учебных заведений; значительной и, зачастую, неоправданной универсальностью формирования рейтинга профессорско-преподавательского состава.

Для комплексного устранения указанных проблемных моментов на основе принципа поэтапного разрешения противоречий целесообразно: модернизировать процесс оценки эффективности финансирования высших учебных заведений; разработать и внедрить механизм распределения полученных высшими учебными заведениями денежных средств по их подразделениям; специализировать процесс формирования рейтинга профессорско-преподавательского состава.

\section{Библиографический список}

1. Николаева E.А., Григорьева И.В. и др. К аспектам влияния оценки эффективности деятельности профессорско-преподавательского состава высшего учебного заведения на укрепление экономической безопасности Российской Федерации / Е.А. Николаева, И.В. Григорьева, И. С. Казимирова, Е.И. Соколова // Экономические науки - Москва: Изд-во ООО «24-Принт», 2019._ № 3.- С. 62-67.

2. Николаева Е.А., Кузнецова Ю.А. и др. Инструменты реализации стратегических инициатив высшего учебного заведения в целях повышения качества образовательного процесса / Е.А. Николаева, Ю.А. Кузнецова, Е.Л. Агибалова, Н.В. Каржанова // Экономические науки - Москва: Изд-во ООО «24-Принт», 2018. - № 9.С. 87-90. 
3. Чернова Е.Г., Ахобадзе Т.Д. Модели финансирования высшего образования и эффективность деятельности университетов. Эмпирическое исследование европейского опыта и отечественная практика / Е.Г. Чернова, Т.Д. Ахобадзе, А.С. Малова, А.А. Салтан // Вопросы образования - Москва: Изд-во Типография «Наука» 2017. - № 3. - С. 37-46.

4. Chmielewski, A. K. (2014), «An international comparison of achievement inequality in within-and between-school tracking systems», American Journal of Education, Vol. 120/3, University of Chicago Press, pp. $293-324$.

5. Sheng, A; Geng, X. (2012). «The new Economics: Meso and Meta», World Economic Forum, 9th October 2012. Geneva, pp. 1-4.

6. Hanushek, E.A. (2011), «The economic value of higher teacher quality», Economics of Education Review, Vol. 30, Elsevier, pp 466-479.

7. $\quad \mathrm{Li}, \mathrm{B}$. (2010). «On micro, meso and macro issues in business ethics», Ethical Research Bimonthly, 4: pp. 25-30.

8. Schütz, G., H. W. Ursprung and L. Wößmann (2008), “Education policy and equality of opportunity”, Kyklos, Vol. 61/2, Wiley-Blackwell, pp. 279-308.

9. Компания «Ernst\&Young» [Электронный ресурс]: аналитические материалы - Официальный сайт компании «Ernst\&Young», 2019.- Режим доступа: https://www.ey.com/ru

10. Рейтинговое агентство «Эксперт РА» [Электронный ресурс]: аналитические материалы - Официальный сайт рейтингового агентства «Эксперт РА», 2019.- Режим доступа: https://raexpert.ru 